\title{
Los amores de Montaigne Tercera escala: los viajes
}

\section{La época}

En escritos anteriores nos referimos a los amores de Montaigne: a Marie de Gournay (Ambrosini, 2018 1, 2019) y a Etiénne de la Boétie (Ambrosini, 20182), este último más conocido como el autor de un escrito explosivo que avivó la llama de la pasión republicana, $L a$ servidumbre voluntaria y que en la pareja con Montaigne representan la consumación del ideal de la amistad exaltada por Aristóteles y Cicerón, ideal que se esforzaron en emular. En vista a la lectura de sus escritos, suponemos que otro gran amor de Montaigne fueron los viajes. Si bien se hizo famoso en la imagen del encierro en la torre del castillo donde ubicó su biblioteca y donde pasaba la mayor parte del tiempo estando en sus propiedades, fue un gran viajero y también apreció mucho los viajes de otros a los que invitaba a su castillo para que le trajeran objetos exóticos y les relataran sus aventuras.

En su biblioteca se registraron varios libros sobre relatos de viajes. En los Ensayos recupera mucha información rescatada de la conversación con aventureros y exploradores que personalmente acudían a su encuentro para relatar sus experiencias por los nuevos territorios conquistados luego de los viajes de Colón y de la ocupación de América. Montaigne nace 42 años después del descenso de Colón en una de las islas del archipiélago de las Bahamas, el 12 de octubre de 1492, nos recuerda De Botton (2001) y en su biblioteca se encontraron libros que Historia general de las Indias de Francisco López de Gómora, la Storia demondo novo de Girolamo Benzoni y Voyage au Brésil de Jean de Léry, referidas al nuevo mundo pero también se encontraban libros de Historia de China, de Portugal, de Persia, de Chipre crónicas de viajes por África, profusamente ilustrados estos libros con figuras de animales exóticos (De Botton, 2001). Estos libros le permiten justificary legitimar sus ideas acerca de la tolerancia entre creencias distintas, toma contacto con la diversidad cultural y evalúa las costumbres de su cultura como parte de un gran abanico de posibilidades entre otras y no como el imperio de reglas naturales y universales.

Cristina Ambrosini / cristinaambrosini@gmail.com / https://orcid.org/0000-0001-6208-0833

Directora de la Especialización y de la Maestría en Metodología de laInvestigaciónCientífica, docentetitular degradoyposgrado, investigadora. Recibido, 20/03/20, Publicado 26/05/20 
Montaigne había llenado su biblioteca de libros que le permitían cruzar las fronteras de los prejuicios" (De Botton, 2001), le permitía superar la visión provinciana, aliviaba la pesadez de la atmósfera opresiva del orden imperante y estas fronteras las cruzó un poco con la imaginación y otro poco a caballo.

Antes de referirnos a los viajes conviene caracterizar brevemente la época ya que no eran tiempos oportunos para andar por los caminos, sobre todo considerando el modo en que viajaba un señor rico, acompañado necesariamente de objetos valiosos, rodeado de un séquito que más bien era un ejército personal. Si el viaje por mar o ríos era peligroso, el viaje por tierra lo era mucho más ya que cada porción del territorio estaba ocupado por alguien que cobraba hasta el uso de los caminos y puentes que, a la vez, tenía permitido aplicar la pena de muerte sin dar mayores explicaciones a nadie. De modo que, si el viajero no era víctima de los ladrones, podría serlo de la Ley local. Las ciudades estaban amuralladas y para entrar había que presentar credenciales y sobre todo presentar las garantías de no haber atravesado regiones asoladas por las distintas pestes ni ser oriundo de Estados enemigos. Otros territorios eran zonas de guerras tribales o directamente de guerras entre Estados. En el caso de Francia. asolaba el terror de las guerras religiosas y de los continuos alzamientos de los campesinos por las abusivas medidas fiscales de los monarcas. Un panorama nada propicio para salir de la seguridad de su castillo para un propietario próspero como era el Señor de la Montaña.
Por otra parte, Montaigne tenía más de una razón para desear ver Roma con sus propios ojos. En tanto escéptico, necesitaba experimentar y constatar por sí mismo lo que había leído y visto en libros y cuadros de su casa sobre la sede del Imperio romano y el poder del Papa Gregorio XIII, el mismo que había celebrado la matanza de San Bartolomé en medallas y cuadros y el creador del nuevo calendario gregoriano.

En 1580 ya hacía 17 años que Montaigne perdiera a su mejor amigo Etiénne de la Boétie víctima de una de las tantas pestes que asoló Burdeos y faltaban 8 años para que iniciara otro viaje donde conoció a la que sería su filled'alliance o hija adoptiva y cuidadora de su obra escrita, Marie de Gournay.

En el verano de 1580 por primera vez Montaigne sale de Francia con destino a Roma. En el camino pasa por Alemania, Austria y Suiza, antes de entrar en Italia. No es este recorrido el camino más corto entre Burdeos y Roma pero podemos pensar que tenía gran interés por recorrer territorios protestantes antes de llegar a la sede del Vaticano. Durante diecisiete meses, hasta noviembre de 1981, recorre 4.800 kilómetros acompañado por un séquito numeroso compuesto por su hermano Bertrand de Mattecoulon, otros tres amigos de su hermano y una docena de sirvientes (De Botton, 2001). Una parte del periplo fue registrado en un diario de viaje por un asistente anónimo. Estas notas fueron encontradas en un viejo arcón en el año 1779 en el castillo de Montaigne por un historiador de la zona, el padre Joseph Prunis. El itinerario incluyó el paso por las 
ciudades de Basilea, Augsburgo, Innsbruck, Verona, Venecia, Padua, Bolonia, Florencia, Siena y finalmente Roma donde llegaron poco antes de iniciarse el invierno de 1580 . Montaigne viajaba como escribía, sin un plan previo (Bakewell, 2010). El Diario de viaje a Italiala versión publicada, registra el comentario de que era imposible apartarse del plan de viaje, sencillamente porque no había un plan. Las limitaciones estaban dadas por las demoras en comenzar el día ya que no le gustaba madrugar, tampoco le gustaba entretenerse con franceses con los que se cruzaran ya que su interés principal era conocer a los nativos de cada lugar y en este interés lamentó no haber llevado a su cocinero entre su séquito, para que aprendiera a cocinar los platos regionales de los lugares por donde pasaron (Bakewell, 2010). Al parecer, ampliar la dieta en el castillo hasta incluir preparaciones exóticas a sus costumbres era un modo de ampliar su mundo, de escapar del encierro local.

Como veremos, también lamentó no haber tomado la precaución de llevar a alguna persona de su estima intelectual, capaz de igualarlo en el interés por las experiencias que encontraran y de seguirle el hilo en sus reflexiones de índole ética y política. Sin duda el pesar por la ausencia de su amigo muerto se hizo sentir con mayor profundidad en esta situación de viajero, especialmente en la estadía en Venecia, la ciudad idealizada por Etiénne de la La Boétie que lo llevó a escribir en los Ensayos "hubiera preferido nacer en Venecia que en Sarlat, y con razón" (Ambrosini, 2018, 1).

\section{El interés filosófico por el viaje}

El registro escrito de este viaje deja constancia del principal interés de Montaigne por observar y comparar las costumbres de los habitantes de las distintas regiones: qué comen, cómo duermen, cómo son los distintos sistemas de calefacción, en qué momentos del día suenan las campanas y otros detalles importantes para deducir de allí su organización social, sus leyes, lo que se considera normal o anormal, verdadero o falso, justo o injusto, en cada localidad. De estas agudas observaciones extrae conclusiones acerca de la naturaleza de lo que se considera normal o razonable o aceptable en cada grupo social. Esta especie de "estudio de campo" le serviría luego a Montaigne para plasmar en los Ensayos el tratamiento de temas donde, a partir del escepticismo, admite que son las costumbres las que moldean la racionalidad, que no hay un sustrato, un principio universal que pueda justificar los principios de la Ética y la Política. En el capítulo XXII "De la costumbre, y de no cambiar fácilmente una ley aceptada" presenta a las costumbres como una fuerza de autoridad. Pues la costumbre es una maestra de escuela violenta y traidora (Montaigne, 2011) .

Montaigne cita costumbres extrañas como algunas de los habitantes de las "nuevas Indias" de comer arañas, hormigas o murciélagos ya que nos escandalizan las costumbres de otros como exóticas o descabelladas, pero podemos advertir que lo que hacemos todos los días también "embota los sentidos" y lo aceptamos como natural por imperio del acostumbramiento. También nos advierte acerca de la importancia del control en la educación de los niños, especialmente en el control de sus juegos para impedir que se instalen hábitos perniciosos. Así afirma:

[...]desde mi infancia me acostumbréa seguir un camino abierto y llano y a disgustarme de mezclar trampa o astucia en mis juegos. (Montaigne, 2011, p.111)

Montaigne dedica numerosas páginas, en este capítulo, a relatar costumbres distintas en distintas comunidades para concluir con una frase que nuevamente podríamos adjudicarle a Wittgenstein cuando afirma 
"Los límites de mi lenguaje significan los
límites de mi mundo"(Wittgenstein, 2004), ya que aquí sostiene:

De donde sucede que aquello que cae fuera de los límites de la costumbre se considera fuera de los límites de la razón. (Montaigne, 2011,p116)

Alude a Platón cuando recomienda reforzar la validez y vigencia de algunas costumbres (la prohibición de los amores desnaturalizados o contra natura) frente a la opinión pública, recurriendo a los poetas para infundir miedos al contar historias terribles en quienes no respetan las buenas costumbres. Las fábulas de Tiestes, Edipo, Macario serían ejemplos de este tipo por sus efectos moralizantes acerca de las graves consecuencias que acarrea la transgresión de las costumbres aceptadas por la comunidad y consagradas como leyes. En estos pasajes, Montaigne se presenta como un conservador, cuando abre sospechas acerca de los intentos de innovar en materia de leyes frente al peligro de alterar el orden vigente o al menos la necesidad de prudencia o sensatez. Dado el impacto negativo que producen estos cambios:

[...] es muy dudoso que cambiando una ley aceptada tal cual, se pueda obtener un beneficio tan importante como la dificultad de eliminarla. Porque un Estado es como una construcción hecha de piezas diversas unidas por tal relación que es imposible mover una sin que todo el cuerpo lo sienta. (Montaigne, 2011, p. 119)

Los que trastornan un Estado son con frecuencia los primeros afectados por su ruina. (Montaigne, 2011,p. 120)

La posición de Montaigne respecto a la autoridad de las leyes parece provenir de una posición pragmática al advertir acerca de un equilibrio entre costos y beneficios, ya que toda alteración del orden vigente podría introducir el caos y la anarquía y, por lo tanto, perjudicar antes que beneficiar la vida social.

Montaigne reconoce que el orden social se sustenta en la necesidad de imponer un orden que "obligue" a las personas a respetar la vida y las propiedades de los demás y que el Estado es necesario dada la precaria o frágil capacidad de los humanos de convivir pacíficamente en ausencia de la fuerza de una autoridad. La imposición de la autoridad de la Ley debe tener la suficiente fuerza como para conjurar el mal mayor que es la anarquía, el desorden y la insurrección generalizada.

\section{Entre la diplomacia y los baños termales}

$\mathrm{Al}$ iniciar el viaje Montaigne tenía 47 años y la publicación de los Ensayos le dio una cierta notoriedad como escritor. Este nuevo prestigio aumentó el interés por sus funciones diplomáticas y políticas en la corte de Enrique III, especialmente frente a su madre Catalina de Medicis, de allí que el primer destino importante del viaje fue Paris y la entrega de uno de los volúmenes de los Ensayos al rey. El otro ejemplar que llevaba entre su equipaje de viaje estaba destinado al Papa Gregorio XIII en Roma. Esta entrega personal se frustró ya que el libro fue incautado por la Inquisición en las puertas de Roma donde para poder entrar le confiscaron varios de los libros que llevaba para ser examinados y pudo recuperarlos luego de cuatro meses. Pero quizás el principal motivo del viaje era la visita a lugares reconocidos de baños termales.

De su padre heredó, además de sus posesiones, la propensión a formar cálculos renales. Para la época, la cura de estos padecimientos era poco probable, pero entre los paliativos 
se recomendaban los baños termales que Montaigne ya conocía algunos en Francia pero los más renombrados estaban en Suiza e Italia. El diario de viaje registra la visita a distintas iglesias protestantes en Alemania y católicas en Italia, también a sinagogas, para conocer las particularidades de los distintos rituales: bautismos, circuncisiones y otras prácticas religiosas de donde extraía abundante información sobre la variedad de costumbres. Trataba de no ser reconocido como extranjero, pero en Augsburgo llamó la atención en una iglesia cuando se sonó la nariz con un pañuelo de tela, un uso no conocido por los lugareños. Estas situaciones lo irritaban ya que pretendía pasar desapercibido, incluso hablando en alemán o italiano, pero sin duda sus modales, su ropa, lo delataban como un noble francés. A diferencia de otros diarios de viaje, en este no hay un registro de las grandes obras de arte y monumentos, en su lugar hay detallados registros de la cantidad de deposiciones en el día que provocó en Montaigne el agua de un lugar o los dolores por la expulsión de un cálculo renal y la posterior calma "tanto por delante como por detrás" de un baño de agua de manantial. Estos detalles sobre acontecimientos fisiológicos, vivencias personales y el registro de variaciones en el modelo de las estufas y de las camas, las distintas salsas y modos de cocinar que encontró contrastan con los diarios de viaje de la época, dedicados a la alabanza de las obras de arte renacentista o de las ruinas dejadas por griegos y romanos. Cuando llegó a Los Alpes intentó desviar la ruta a Roma para ir a Polonia y Grecia pero el resto del séquito, quejoso de la prolongación del viaje, insistió en hacer lo que todos los viajeros: seguir a Roma y volver a casa por lo que resignó este objetivo y se encaminaron allí. Luego Montaigne se lamentaría de no haber contado con compañeros de viaje adecuados, no tener con quien intercambiar las impresiones de sus experiencias y enriquecer con una charla amena las horas de descanso. El séquito se parecía más a un ejército particular que a verdaderos compañeros de viaje. Cruzaron Los Alpes por el paso de Brenner y ya en Italia pasaron por Verona, Vicenza, Paduay finalmentellegaron a Venecia, la que hubiera sido La Meca para Etiénne de La Boétie, cuna de las libertades políticas para su difunto amigo. Allí tomó contacto con una de las más famosas cortesanas, Verónica Franco, autora del libro Lettere familiare e diversi del que le regala un ejemplar. Este compendio de escritos comprende 50 cartas y dos sonetos dedicados a Enrique III, con el que ella había tomado contacto antes de que fuera rey de Francia. Montaigne sentía especial afinidad por estas mujeres inteligentes, cultas que, como las hetarias griegas, acompañaban a los hombres de poder. En el caso de Verónica Franco su mecenas fue el Duque de Mantua quien supo reconocer sus méritos intelectuales y le permitió editar una colección de Poemas Terze rime que alcanzó gran popularidad. Al igual que en otros casos, como el de Corisande, la cortesana ligada a Enrique de Navarra (Ambrosini, 2019), Montaigne disfrutaba de la conversación y el trato amistoso con estas mujeres allegadas a hombres de poder, así como también contaba con la confianza y amistad de otras mujeres decididamente poderosas como Catalina de Medicis y luego, a partir de 1888 contó con la devoción de su fille d'alliance y albacea de los Ensayos, Marie de Gournay. Luego de la estadía en La Serenisima, Montaigne y su séquito pasaron por Florencia, Ferrara y Bolonia. Antes de llegar a Roma también pasaron por Siena y Viterbo. El 5 de noviembre de 1580 llegaron a las puertas de Roma y como registro del gran entusiasmo consta en el diario de viaje que ese día Montaigne, visiblemente impaciente, hizo levantar a todos tres horas antes del amanecer para recorrer el último tramo del camino hasta llegar al comienzo del día a ver las ruinas del Imperio romano. Antes de entrar a la gran ciudad, tuvieron que soportar una minuciosa requisa de todo lo que traían y les fueron incautados varios de los libros 
que llevaban, incluido el ejemplar de los Ensayos destinado al Papa. Afortunadamente no llevaba nada incriminatorio ni herético a pesar de haber pasado por Alemania, allí compró libros cristianos. Entre las variadas actividades a las que se dedicó en Roma, Bakewell destaca el encuentro con prostitutas, fuentes inagotables de información valiosa y la audiencia con el Papa Gregorio XIII que por pedido de Montaigne quedó registrado hasta en sus mínimos detalles en el diario de viaje. En una ocasión presenció un exorcismo y en otra el colgamiento de un reo llamado Catena que entre sus víctimas se encontraban dos monjes capucinos. En los Ensayes consta el registro del ensañamiento de los presentes con el cuerpo muerto del reo como un caso raro de tortura sobre el cuerpo inerte del difunto. Finalmente dejó Roma el 19 de abril de 1581 para ir a los bańos de La Villa cerca de Lucca, donde permaneció 1 mes tratando de aliviar allí sus dolencias. En este lugar es donde recibió una carta donde le comunicaban que había sido elegido en su ausencia como el Alcalde de la ciudad de Burdeos. No era esta noticia precisamente lo que esperaba ni deseaba conocer ya que significaba definitivamente la interrupción del viaje para volver a su ciudad y hacerse cargo de esta pesada carga. En lugar de emprender rápidamente la vuelta, se demora volviendo a Roma pero allí recibe una segunda carta donde lo instigan a volver con urgencia y por orden del Rey a cumplir con las responsabilidades de esta alta investidura. En los Ensayos, retomados en la escritura cuando regresa a sus propiedades, registra el disgusto que le causó este ofrecimiento y los intentos que hizo por rechazar el nombramiento sin ningún resultado. Tampoco le tomó prisa la vuelta, se demoró en la visita de varias ciudades italianas antes de entrar en Francia. Registra la llegada al castillo el 30 de noviembre de 1581 cuando escribe "he llegado a mi casa" luego de un viaje de "diecisiete meses y ocho días" (Bakewell, 2010).

\section{El amor a los viajes}

Como en el caso de Ulises en La Odisea, el cumplimiento del deber devuelve a Montaigne a sus obligaciones antes de lo deseado. Allílo esperan su esposa, su hija, los ciudadanos de Burdeos, el mismo rey, para tomar el mando en tiempos de intolerancia, de inestabilidad política y hasta del azote de pestes que diezmaban las poblaciones. El impulso nómade y errante del viajero debe ser resignado por el momento.

En el transcurso de su viaje llevó, por la mano de su secretario y por la propia, un meticuloso registro de todo lo sucedido. Al parecer, este diario de viaje no estuvo destinado por Montaigne a su publicación. Puede ser que tuviera por finalidad recoger la información para futuros escritos, para ampliar los Ensayos, para servir de guía a otros viajeros. Las meticulosas descripciones de los efectos fisiológicos del viaje sobre su persona llevan a especular que puede ser visto como un registro médico ya que detalla, a veces con precisión que hoy consideraríamos "científica", la cantidad y color de la orina, las sensaciones del paso de la orina por su aparato urinario, el sonido de la emisión al caer, el número de ventosidades, la cantidad de deposiciones, el efecto de la ingesta de agua mineral sobre su estado anímico.

Todos estos aspectos corporales parecen indiscretos e inoportunos para el lector culto pero nos acercan al reconocimiento de la corporalidad, a la gravitación de la fisiología sobre el pensamiento y las consecuencias en el ejercicio de la racionalidad. Esta meticulosidad, casi maníaca, contrasta con la ausencia de descripciones sobre las obras de arte y las ruinas del antiguo imperio romano. Parece más interesado en registrar fenómenos naturales como el ruido del agua y los distintos tipos de fuentes encontradas en los palacios italianos, en la disposición de 
los jardines, que en las estatuas o pinturas. Los viajes le permitieron tomar contacto con otros modos de expresar el mundo, de organizar la vida social, de manifestar las ideas y de concretar los ideales de vida de las distintas gentes que encontró en el camino. También le permitieron los viajes ejercer la tolerancia hacia lo diverso de la condición humana. En el paso por palacios, posadas y hasta en el Vaticano experimentó la hospitalidad en sus distintas manifestaciones culturales. A pesar de sus esfuerzos por pasar desapercibido fue recibido como un extranjero, un huésped, donde pudo practicar hacerse entender en el lenguaje local no tanto para conocer el idioma sino para investigarlo en sus múltiples usos.

La condición de "filósofo errante" debe ser la que más atrajo al autor de El viajero ysu sombra a los escritos de Montaigne. Sabemos que Nietzsche profesa un especial afecto por Montaigne y que lleva los Ensayos como uno de los pocos libros que lo acompañaron en sus años de apátrida junto con Sthendal y el Abate Galiani. En una carta a su madre y hermana, citada por De Botton (2010) expresa: "hoy no vive nadie por quien yo tenga interés; las personas que me agradan han muerto hace mucho, mucho tiempo, por ejemplo: el abate Galiani o Henri Beyle o Montaigne". Podemos preguntarnos si Nietzsche tuvo su Etiénne de la Boétie o su Marie de Gournay, En este punto, la más segura candidata es Cosima Wagner antes que Lou Salomé con la que rompió de manera unilateral el vínculo y no continuó el contacto ni físico ni epistolar. A diferencia de Nietzsche, Montaigne es un viajero que tiene un lugar donde volver, ocupaciones y compromisos que demandan que abandone el viaje y vuelva a casa mientras que para Nietzsche la errancia es una condición vital ya que no tiene ninguna casa que reclame su presencia. Como el personaje de su libro $A s i$ habló Zarathustra, el viaje es una experiencia de búsqueda de compañeros de viaje. Más que un viajero parece un exiliado. Montaigne, en cambio, no necesito salir de su chateau para tener amigos, tuvo uno que lo acompañó el resto de su vida, en la memoria y en otro viaje, en 1588 conocerá a una mujer que reunirá en sí misma los caracteres de una hija, una amante y una amiga (Ambrosini, 2019). En el caso del encuentro con Marie, luego del viaje a Paris y de la residencia por 6 meses en Gournay-sur-Aronde, al norte de Paris, debe retornar al castillo y ya en los últimos cuatro años de su vida, hasta morir, el 13 de septiembre de 1592, será el intercambio de cartas el lugar de encuentro con Marie de Gournay quien recibirá como legado toda su obra escrita.

De este modo cerramos el recorrido por lo que consideramos los tres amores de Montaigne, dos son personas que enriquecieron y dieron sentido a su vida afectiva de un modo completamente decisivo para su obra escrita: Etiénne de la Boétie y Marie de Gournay. El tercer amor, los viajes, será un amor compartido por muchos otros filósofos entre los que no se cuenta Immanuel Kant quien, como cuenta la leyenda, nunca se alejó de su ciudad natal, Königsberg, pero al parecer eso no hizo mella en su producción 
filosófica ya que en el encierro provinciano de la alejada ciudad prusiana contaba con la información necesaria como para dar un giro copernicano en el pensamiento occidental. Al parecer su modo de viajar era otro que el de Montaigne pero tanto uno como otro dejaron sus huellas en la Historia de la Humanidad.

\section{Bibliografía}

—Ambrosini, Cristina, (2018. 1), "Marie de Gournay, Escritos sobre la igualdad y en defensa de las mujeres", en Revista Perspectivas Metodológicas, Vol. 18, Núm. 21 (2018 a,)http://revistas.unla.edu.ar/ epistemologia/issue/view/129

-Ambrosini, Cristina, (2018. 2), "Los amores de Montaigne Primera escala: Etiénne y Michel" en Revista Perspectivas Metodológicas, Vol. 18, Núm. 22 (2018 b.)http://revistas.unla.edu.ar/epistemologia/article/view/2061

- Ambrosini, Cristina, (2919), "Los amores de Montaigne Segunda escala: Michel y Marie 1588-1592 los últimos 4 años de la vida de Montaigne", en Revista Perspectivas Metodológicas, 2019, http:// revistas.unla.edu.ar/epistemologia/article/ view/2388/1492

- Bakewell, Sarah, (2010), Cómo viviro Una vida con Montaigne, Barcelona, Ariel, - De Botton, Alain, (2001), Las consolaciones de la filosofí, Madrid, Taurus, —Edwuards Jorge, (2011), La muerte de Montaigne, Buenos Aires, TusQuests, —Montaigne Michel de, (2011), Ensayos, Buenos Aires, Losada,

- Montaigne, Michel, Diario de viaje a Italia, en versión digital en https://www. cairn.info/journal-de-voyage-de-michelde-montaigne--9782130443001-page-V. htm? contenu=plan, consultado el $28 \mathrm{de}$ enero de 2020

- Verónica Franco en EcuRed disponible en https://www.ecured.cu/Ver\%C3\%B3nica Franco, consultado el 28 de enero de 2020

- Wittgenstein, Ludwig, (2004), Tractatus lógico-philosophicus, Madrid, Alianza Editorial, 